\title{
Bourses annuelles d'aide à la mobilité internationale de l'Institut français d'histoire en Allemagne (Francfort)
}

\section{OpenEdition}

\section{Journals}

Édition électronique

URL : http://journals.openedition.org/ifha/7981

DOI : $10.4000 /$ ifha.7981

ISSN : 2198-8943

Éditeur

IFRA - Institut franco-allemand (sciences historiques et sociales)

Édition imprimée

Date de publication : 31 décembre 2014

ISSN : 2190-0078

Référence électronique

« Bourses annuelles d'aide à la mobilité internationale de l'Institut français d'histoire en Allemagne (Francfort) », Revue de l'IFHA [En ligne], 6 | 2014, mis en ligne le 31 décembre 2014, consulté le 02 mai 2019. URL : http://journals.openedition.org/ifha/7981; DOI : 10.4000/ifha.7981

Ce document a été généré automatiquement le 2 mai 2019.

(CIFHA 


\section{Bourses annuelles d'aide à la mobilité internationale de l'Institut français d'histoire en Allemagne (Francfort)}

Date limite de dépôt des candidatures : $1^{\text {er }}$ février 2015

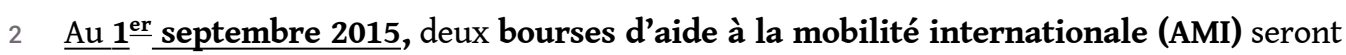
ouvertes à l'Institut français d'histoire en Allemagne (Francfort-sur-le-Main, Allemagne).

Peuvent faire acte de candidature des doctorants en histoire ancienne, médiévale, moderne et contemporaine ayant engagé une recherche qui concerne l'histoire ou l'historiographie allemande ou franco-allemande, ou bien encore dans des disciplines qui engagent une forte démarche historique.

4 La sélection des dossiers se fera sur examen des projets de recherche par le conseil scientifique du centre. Le dossier de candidature, composé de deux documents, est disponible en ligne sur le site de l'IFHA (www.ifha.fr - rubrique « postes-bourses »).

5 Ce poste de boursier d'aide à la mobilité internationale n'est pas un contrat de travail, et doit être entendu dans le sens d'une libéralité. Ni l'Ambassade de France, ni le Ministère des Affaires Etrangères ne peuvent être considérés comme employeur. En effet, la période couverte par l'aide n'est en aucun cas assimilée à une période d'activité salariée ouvrant droit aux cotisations de sécurité sociale et aux allocations de chômage.

6 Cette AMI est d'une durée d'un an. Une prolongation d'une année est possible, sur proposition du directeur et après avis du conseil scientifique de l'Institut.

7 En-dehors de leur propre recherche, les bénéficiaires peuvent en tant que de besoin, participer aux activités scientifiques communes de l'IFHA et de son université partenaire à Francfort.

8 Le montant mensuel de l'aide à la mobilité internationale est de $\underline{1} \underline{400 \text { euros. }}$. Le candidat retenu pourra bénéficier de la prise en charge de son billet aller pour rejoindre son poste et de son billet retour en fin de mission (dans la limite d'une somme forfaitaire de 300 
euros par trajet), ainsi que du remboursement forfaitaire du transport de ses bagages jusqu'à hauteur de $200 €$.

9 Les dossiers se composent de deux documents à télécharger sur le site www.ifha.fr : un formulaire de candidature et un formulaire pour les lettres de recommandation. Des renseignements peuvent être obtenus au Ministère des Affaires Étrangères auprès de Monsieur Philippe Devaud (philippe.devaud@diplomatie.gouv.fr) ou auprès de l'Institut français d'histoire en Allemagne: Tel: +49 $-(0) 69 / 79831900$ E-Mail: ifha@institutfrancais.de. Le dossier doit être rempli en $\mathbf{2}$ exemplaires :

11 - 1 exemplaire, accompagné de toutes pièces utiles (publications, originaux des attestations des directeurs de recherche...) et d'un C.V. comportant in fine l'intitulé du projet adressé au Directeur de l'Institut français d'histoire en Allemagne: JohannWolfgang-Goethe-Universität Franfkurt, Campus Westend, Grüneburgplatz 1, IG-FarbenHaus, Postfach 42, D-60623 Frankfurt am Main).

12 - 1 exemplaire, accompagné d'un C.V., des copies des attestations et de l'intitulé du projet de recherche adressé à la Sous-Direction des échanges scientifiques et de la recherche Ministère des Affaires Étrangères - DGM/ATT/RECH - 27 rue de la Convention - CS 91593 - 75732 PARIS CEDEX 15.

Date limite de dépôt des candidatures : $1^{\text {er }}$ février 2015 (voie postale uniquement) 